\title{
THE PATTERN OF PENETRATION AND ASPIRATION IN ACUTE STROKE SURVIVORS
}

\author{
$\underline{L i s a}_{\text {Everton }}{ }^{1}$, Jacqui Benfield ${ }^{2}$, Emilia Michou ${ }^{3}$, Shaheen Hamdy ${ }^{3}$, Philip M Bath ${ }^{1}$ \\ ${ }^{1}$ Stroke Trials Unit, Division of Clinical Neurosciences, School of Medicine, University of \\ Nottingham, UK \\ 2 Division of Medical Sciences \& GEM, School of Medicine, University of Nottingham, UK \\ 3 Division of Diabetes, Endocrinology and Gastroenterology, School of Medical Sciences, \\ University of Manchester, UK
}

Background and Aims: Aspiration is common in acute stroke survivors with dysphagia, is associated with increased pneumonia rates, and is an independent predictor of mortality. However, studies evaluating the nature and pattern of penetration and aspiration poststroke are lacking.

Method: The Penetration-Aspiration Scale (PAS) was used to rate baseline videofluoroscopic swallowing studies of 17 dysphagic stroke survivors from the STEPS trial of pharyngeal electrical stimulation (onset $<14$ days, mean 74 years). Analysis was performed on $6 \times 5 \mathrm{ml}$ boli and $1 \times 50 \mathrm{ml}$ bolus (thin fluids with contrast agent at $40 \%$ wt/vol), recorded at $25 \mathrm{f} / \mathrm{s}$. Every swallow to clear each $5 \mathrm{ml}$ or $50 \mathrm{ml}$ bolus was counted, given a PAS score and labelled a primary or secondary (clearing) swallow.

Results: In total, 285 swallows were viewed. Due to poor image quality, $7 \%$ of swallows were excluded. At a bolus level, for $5 \mathrm{ml} / 50 \mathrm{ml}$ swallows, results showed $68 \% / 42 \%$ normal swallows, $14 \% / 27 \%$ penetration and $18 \% / 31 \%$ aspiration respectively. At a subject level, $5 \mathrm{ml}$ : only 3 patients scored within normal limits for all boli; $50 \mathrm{ml}$ : no subject swallowed without showing penetration or aspiration at some point. Higher penetration and aspiration scores occurred on $50 \mathrm{ml}$. Aspirated material was rarely fully cleared, even in those subjects who demonstrated a cough response $(5 \mathrm{ml}: 2 \%, 50 \mathrm{ml}$ : $0 \%)$.

Conclusion: Aspiration in post-stroke dysphagia appears to fluctuate in presentation within and between boli. Bedside assessments should take into account variability and sample enough swallows. In addition, clinicians should not assume coughing clears aspirated material. Quality of image capture must be optimised for future studies. 